\title{
Recent advances in anterior chamber angle imaging
}

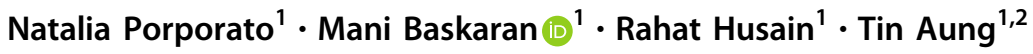

Received: 27 September 2019 / Accepted: 9 October 2019 / Published online: 30 October 2019

(c) The Author(s), under exclusive licence to The Royal College of Ophthalmologists 2019

\begin{abstract}
Differentiating the two main forms of primary glaucoma (open-angle and closed-angle glaucoma) depends on the correct assessment of the anterior chamber angle (ACA). This assessment will determine the management plan and prognosis for the disease. The standard method of examining the angle has been, for many years, slit-lamp gonioscopy. This method, although clinically still useful, is less robust for patient follow up and clinical research, given its low reproducibility. Several imaging technologies have been developed in recent years to improve the evaluation of the ACA and overcome the shortcomings of gonioscopy. These recent advances include three-dimensional and $360^{\circ}$ analysis by Swept-Source OCT (SS-OCT, CASIA, Tomey, Nagoya, Japan), the introduction of deep learning algorithms for automatic imaging classification and new goniophotographic systems. SS-OCT allows for the first time the assessment of the circumferential extension of angle closure with moderate to good diagnostic performance compared with gonioscopy. Deep learning algorithms are showing promising results for the automation of imaging analysis, and may potentially save physicians' time in regards of the interpretation of the images. Lastly, goniophotograph systems have the distinct advantage of recordability of gonioscopic findings and are most closely matched to the findings of slit-lamp gonioscopy.
\end{abstract}

\section{Introduction}

The categorization of primary glaucoma into open angle or closed angle relies on the anatomy of the anterior chamber angle (ACA). The assessment of the ACA divides the disease into two major types: primary open-angle glaucoma (POAG) and primary angle-closure glaucoma (PACG)depending on whether the ACA is open or closed. Differentiating these two conditions is important because they have different management strategies and prognoses [1]. PACG is regarded as more 'aggressive' disease than POAG. In evidence for this, PACG accounts for $50 \%$ of the global bilateral blindness due to glaucoma, despite being less prevalent than POAG [2]. Furthermore, it is estimated that the number of people with PACG worldwide will reach 32.04 million in 2040, an increase of 58.4\% compared with 2013 [3]. This combination of an aggressive, blinding

Tin Aung

aung.tin@singhealth.com.sg

1 Singapore Eye Research Institute/Singapore National Eye Center, Singapore, Singapore

2 Department of Ophthalmology, Yong Loo Lin School of Medicine, National University of Singapore, Singapore, Singapore disease, and increased global prevalence marks PACG as a disease that warrants attention by the global ophthalmic research community. Crucially, in contrast to POAG, PACG is potentially a preventable disease if the progressive angle closure process can be thwarted in the early stages of the disease [4]. Options for averting the process (i.e., opening the ACA or slowing down its closure) include laser peripheral iridotomy (LPI), laser iridoplasty or cataract extraction (with or without goniosynechialysis) [5-8]. In order to determine the effect of these interventions on the ACA, it is important that an objective, repeatable, and quantifiable method of angle assessment is used. The standard method of examining the angle has been, for many years, manual slit-lamp gonioscopy using a goniolens. This method, although clinically still useful, is less robust for patient follow up and clinical research, given its many limitations (Table 1). Several imaging technologies have been developed in the recent years to improve the assessment of the ACA. This has obvious advantages not only in terms of diagnosis of angle-closure but also to monitor the anatomical effect of any intervention. These recent advances include three-dimensional and $360^{\circ}$ circumferential analysis of the ACA by swept-source OCT (SS-OCT, CASIA, Tomey, Nagoya, Japan; Fig. 1), the introduction of deep learning systems for imaging classification and new goniophotograph systems (Fig. 2). 


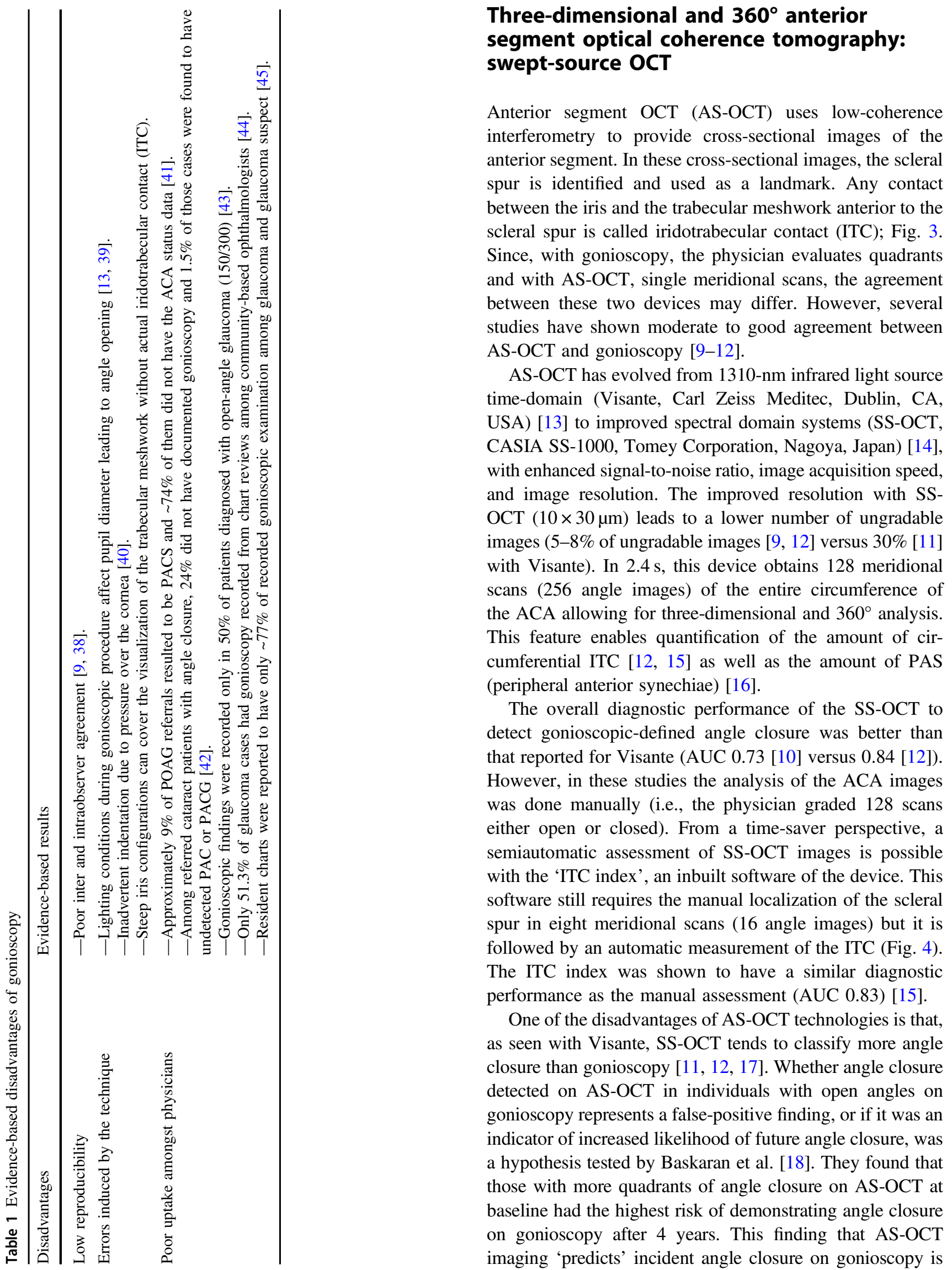



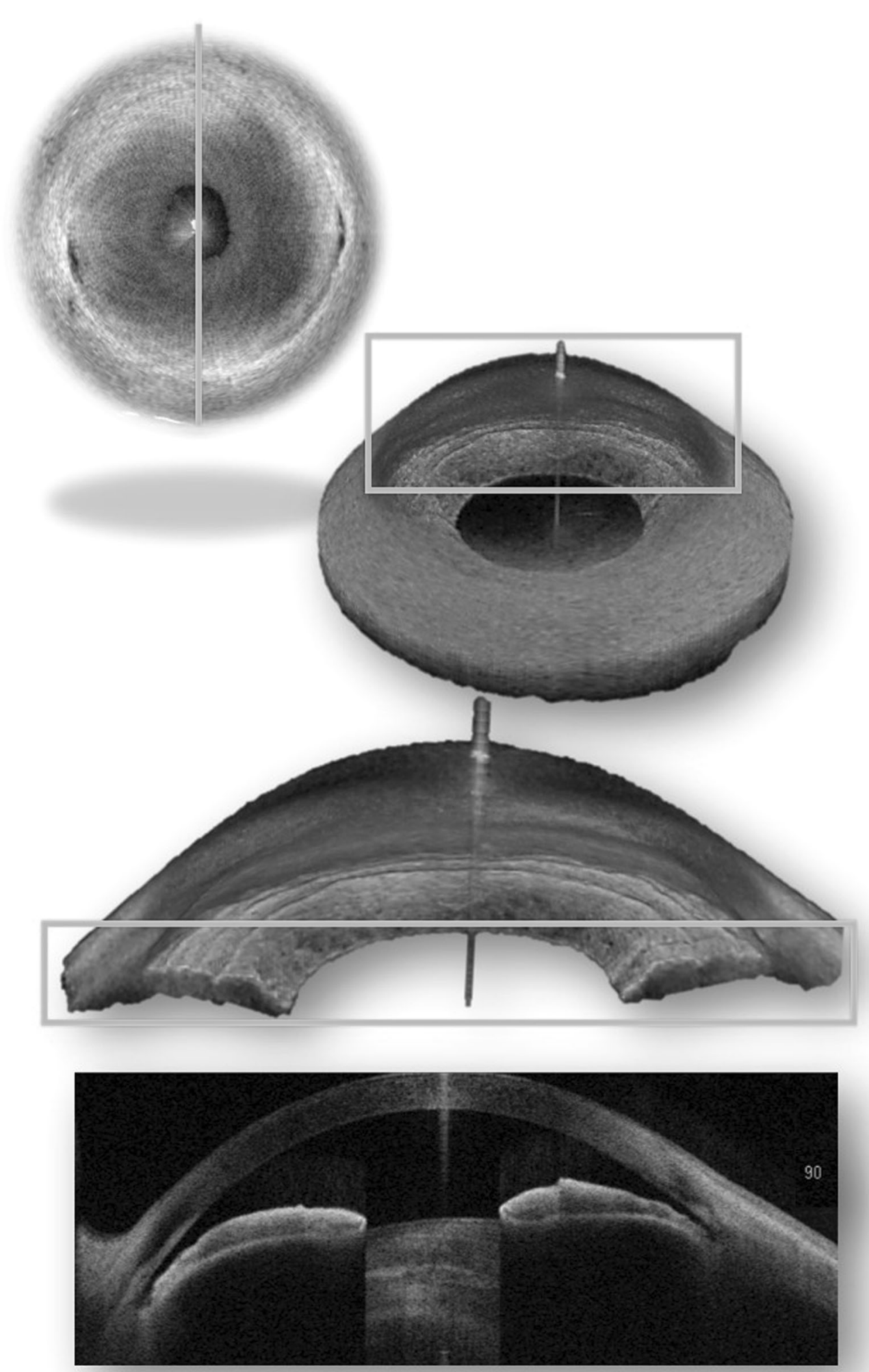

Fig. 1 Cross-sectional Swept Source-OCT (CASIA SS-1000, Tomey Corporation, Nagoya, Japan) image 
supported by the fact that none of the subjects with open angles on AS-OCT demonstrated gonioscopic angle closure on follow-up. Interestingly, it was shown in a recent large community-based study that this disagreement in angle closure diagnosis between gonioscopy and SS-OCT was associated with the configuration of the anterior chamber. Anterior chamber depth (ACD) was found to be a factor highly associated with diagnostic disagreement (OR 9.31) and it was observed that gonioscopy and SS-OCT methods

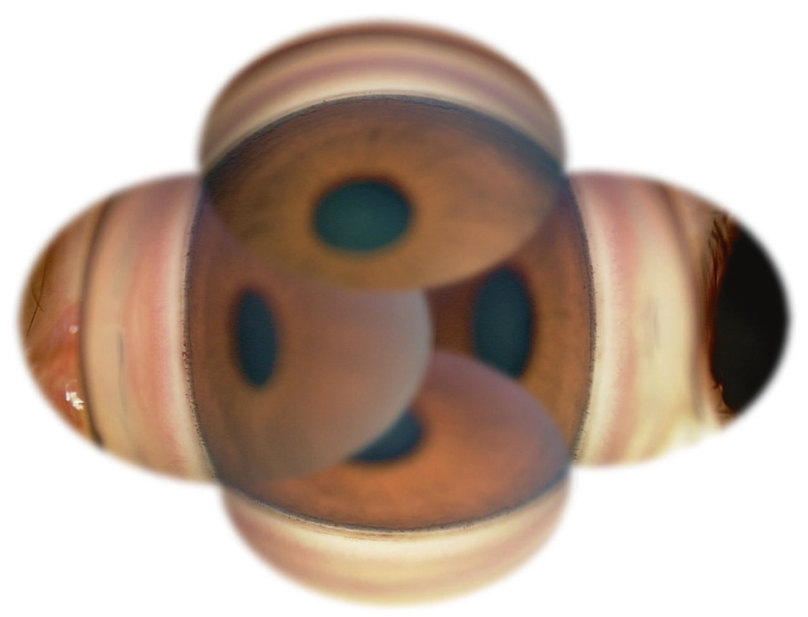

Fig. 2 Frontal view of goniophotograph systems (EyeCam, Clarity Medical Systems, Pleasanton, CA) showing four quadrants open based in the visibility of the posterior trabecular meshwork tend to agree in the angle status diagnosis when these eyes have either shallow $(\leq 2.2 \mathrm{~mm})$ or deep anterior chambers $(\geq 2.7 \mathrm{~mm})$. However, they seem to disagree when the ACD is around $2.4 \mathrm{~mm}$, i.e., an observer performing gonioscopy may see these angles as open while on SS-OCT it may be closed [19]. This finding can be explained by the differences in landmarks, technique and definition of angle closure between both technologies. However, we do not know to this date which technology is identifying better the pathological angle closure eyes.

One of the biggest advantages of the $360^{\circ}$ analysis done by SS-OCT is the ability to identify PAS. Lai et al. [16] quantified the area and the degree of PAS involvement and showed that it was possible to discriminate synechial angle closure from appositional angle closure by varying the lighting condition during the SS-OCT imaging. Furthermore, they demonstrated that the measurements of the area and the degree of PAS involvement were reproducible. Synechial angle closure often exhibits an obtuse configuration, whereas appositional closure almost always assumes an acute configuration. A recent study also showed how the angle configuration and PAS extension changes after surgery, as seen by SS-OCT. Tun et al. employed the use of SS-OCT to assess the circumferential reduction of ITC area after phacoemulsification (PE) alone compared with PE and goniosynechialysis (PE + GSL) in eyes with synechial PACG. They found that PE + GSL surgery resulted in a greater reduction of ITC (and the extent of
Fig. 3 SS-OCT image showing the localization of the trabecular meshwork (yellow area) and the scleral spur (red dot) and SSOCT scan (bottom image) showing a closed angle (yellow frame) defined by the iridotrabecular contact anterior to the scleral spur
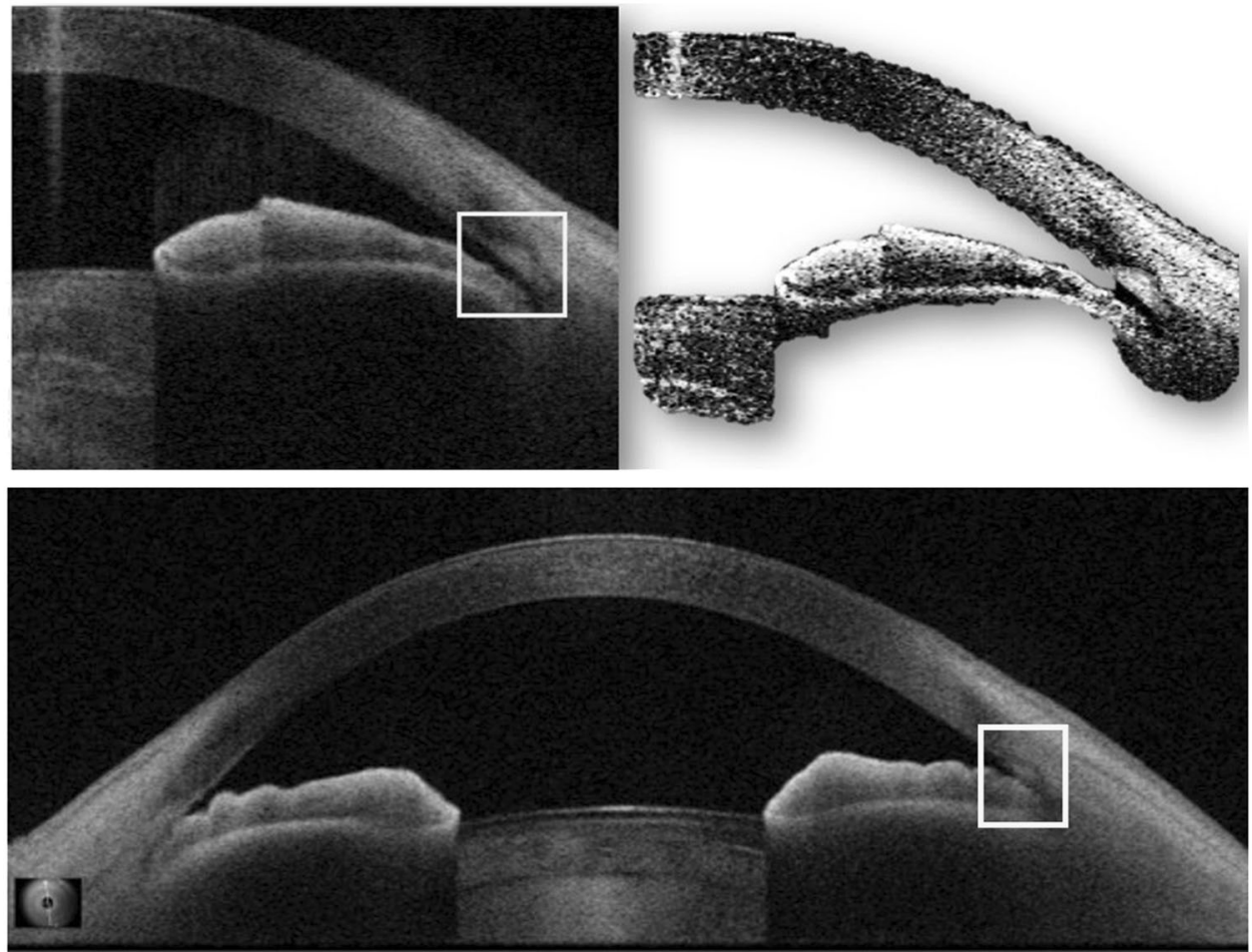


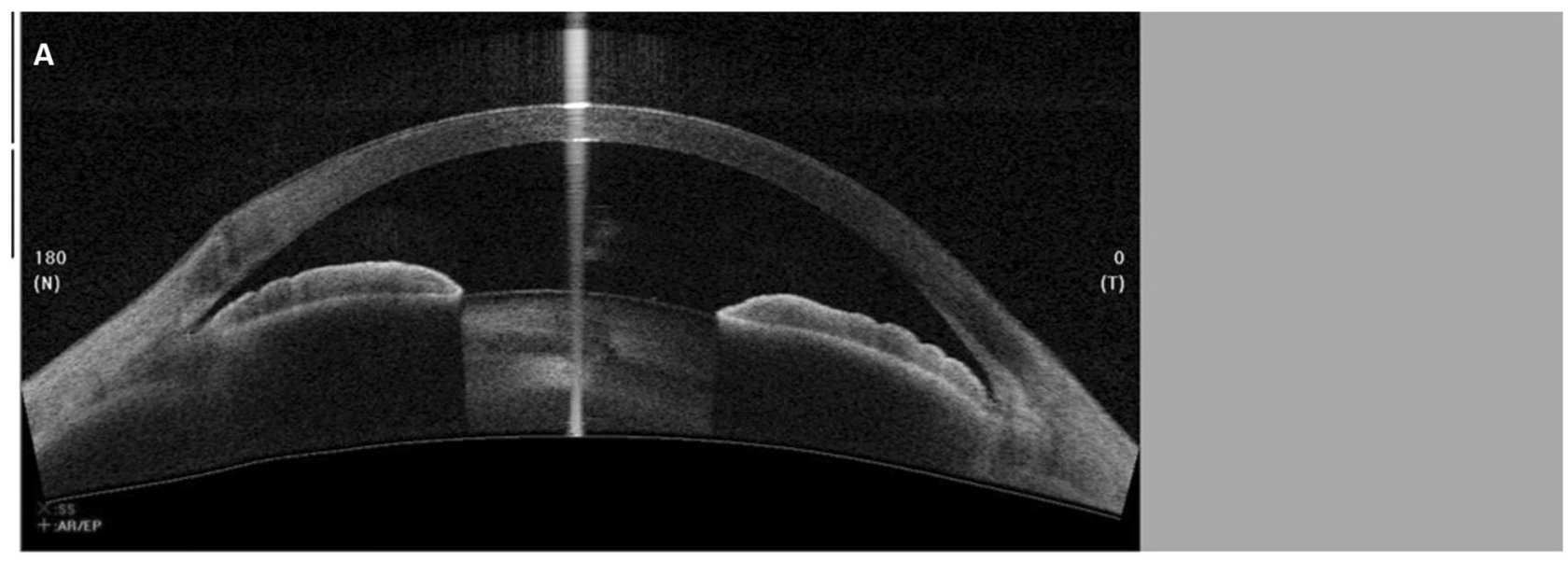

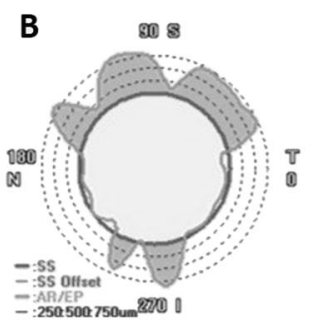

Fig. 4 The iris-trabecular contact (ITC) index analysis. a SS-OCT meridional scan. The colored ' $x$ ' represents the scleral spur (SS) marking, and the ' + ' represents the ITC end point (EP). Both points are marked by the observer in eight meridional scans. b The ITC chart with the blue shadow area represents the amount and distribution of

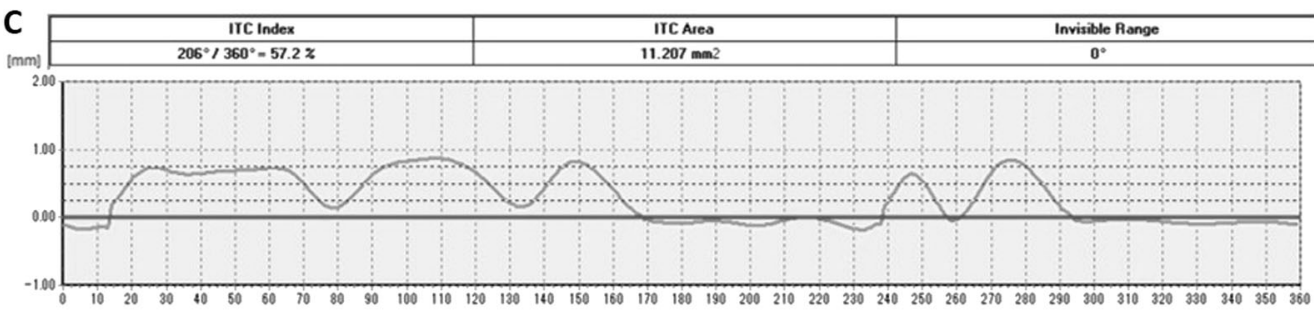

ITC. c The ITC graph with the $y$-axis represents ITC (in arbitrary units), and the $x$-axis represents the degree of the angle. The distance between each point of the green line and the red line (representing the scleral spur) denotes the amount of angle-closure (measured as the ITC index)
Fig. 5 Swept source OCT image of a case of peripheral anterior synechiae pre (a) and post (b) phacoemulsification with goniosynechialysis
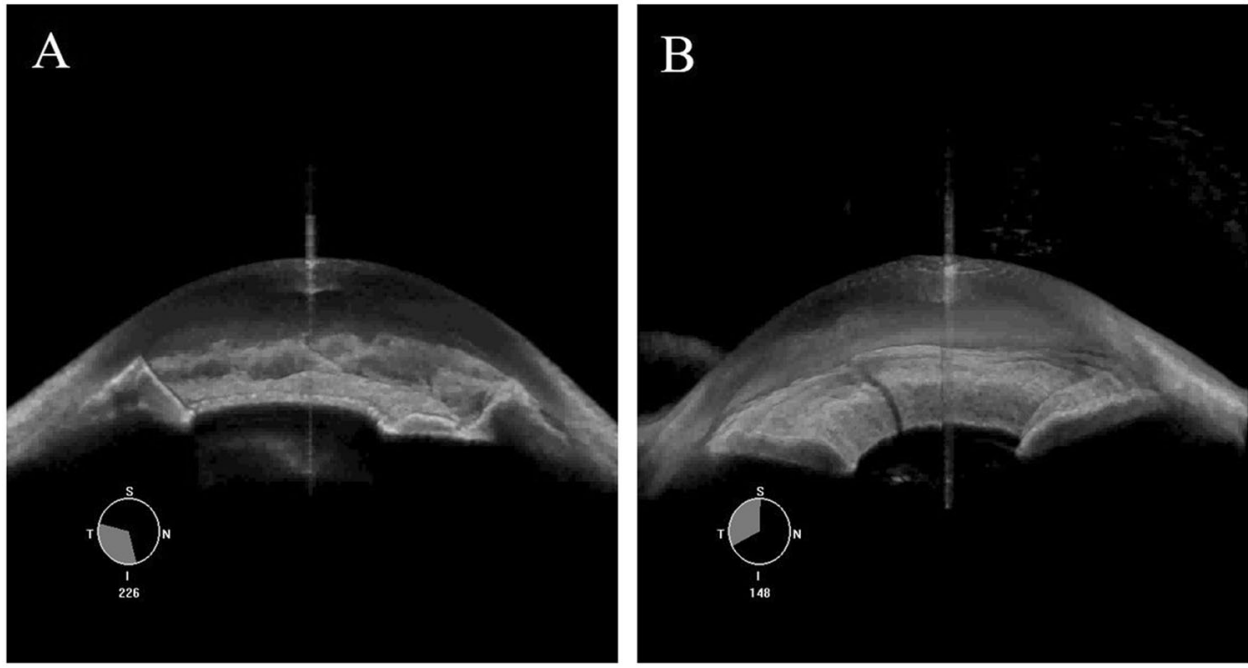

PAS) than PE alone after adjusting for age, gender and baseline IOP, baseline PAS and preoperative pupil diameter (Fig. 5).

\section{AS-OCT quantitative parameters}

Some of the parameters commonly used in AS-OCT imaging (Fig. 6) are ACD, anterior chamber width, and lens-related parameters ( $\mathrm{LV}$, lens vault and lens thickness, LT). Specific parameters to describe features of the angle includes the angle opening distance (AOD), the angle recess area, and the trabecular-iris space area. These parameters can be measured at varying intervals anterior to the scleral spur, most frequently at 500 or $750 \mu \mathrm{m}$ anterior to the scleral spur (i.e., AOD500, AOD750). All these parameters have shown to be significantly associated with angle closure [20-23] but only ACD and LV performed similarly high 
Fig. 6 SS-OCT image showing the measurements of anterior chamber depth (ACD), lens vault $(\mathrm{LV})$, anterior chamber width $(\mathrm{ACW})$, iris thickness at $750 \mu \mathrm{m}$ from scleral spur (IT750, SS), angle opening distance (AOD), trabecular iris space area (TISA), and angle recess area (ARA)

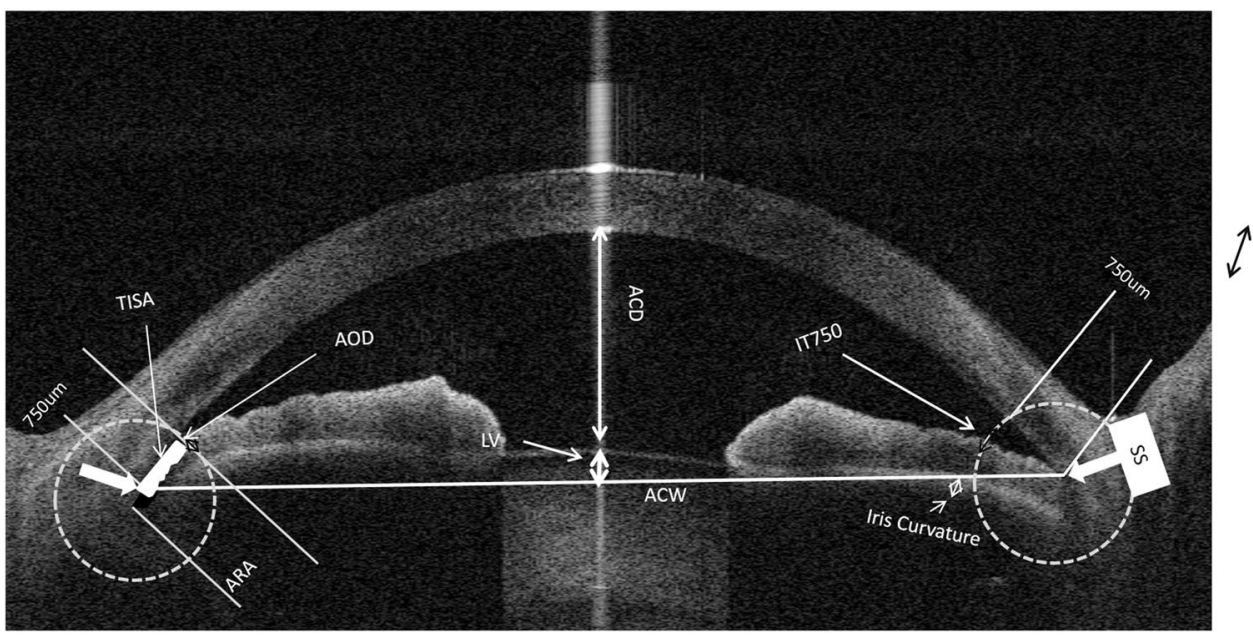

enough to diagnose gonioscopic closed angles [24]. Lens vault measures the distance from the anterior lens surface to a line drawn between the two scleral spurs. Moreover, these parameters helped to subgroup different types of angle closure. Three distinct angle closure subgroups were identified, characterized by larger iris area (subgroup 1), larger LV (subgroup 2), and elements of both subgroups (subgroup 3). Subgroup 1 was characterized by a relatively greater iris area and it may result in angle crowding and subsequent angle closure in some persons. The predominant mechanism for subgroup 2 was a large LV even though iris area was smaller than seen in subgroup 1, suggesting more of a pushing mechanism. Subgroup 3 likely had contributions from all four components to develop phenotypic angle closure [25]. These findings are not only helpful in elucidating mechanisms of angle closure but also help guide clinicians as to which sub-type might benefit from which intervention. For example, for a patient with high lens vault mechanism predominating then lens extraction (all other things being equal) might be a preferred management plan.

\section{Automatic detection of angle closure based on machine learning}

A recent development in ACA imaging is the ability to perform qualitative and quantitative analysis of AS-OCT images based on deep learning algorithms that use raw images (pixel by pixel) obtained from the imaging device.

Niwas et al. [26] developed a deep learning algorithm for mechanistic classification of raw AS-OCT images. The algorithm aimed to identify the major mechanisms of angle closure: exaggerated lens vault, pupil block, thick peripheral iris roll, and plateau iris. It demonstrated $89.2 \%$ accuracy and $89 \%$ sensitivity and specificity compared with mechanism-based morphologic characteristics classified by glaucoma specialists as the gold standard.

From a diagnostic perspective, two large studies were conducted using Visante and SS-OCT. Fu et al. [27] studied a total of 4135 Visante AS-OCT images from 2113 subjects with a deep learning angle-closure detection system and found an AUC of 0.96 with a sensitivity of $90 \%$ and a specificity 92\%, against physicians grading of AS-OCT images as the reference standard. Xu et al. [28] tested multiclass convolutional neural network classifiers to automatically detect gonioscopic angle closure in SS-OCT images. The best-performing classifier was developed by applying transfer learning and it achieved an AUC of 0.93 on the cross-validation dataset. For detecting angle closure disease, based on two- and three-quadrant definitions, the classifier achieved AUCs of 0.96 and 0.95 , respectively, on the test dataset. The authors concluded that these methods could be used to automate clinical evaluations of the ACA and improve angle closure detection in high-risk populations, particularly in areas with poor access to eye care.

\section{Goniophotographic systems}

In view to overcome the lack of recordability with slit-lamp gonioscopy, different systems of goniophotography have been developed in recent years. These include two commercially available devices EyeCam (Clarity Medical Systems, Pleasanton, CA) and NGS-1 automated gonioscope (NIDEK Co, Gamagori, Japan), and two prototypes; the GonioPEN and Axicon lens assisted gonioscopy adapted to the slit-lamp. The main problem with these types of technologies is the limited resolution of the TM due to focus (all of them require several images to select the best one, NGS-1 does it semiautomatically) and the interpretation of the images by the physician. 
Fig. 7 EyeCam image of the inferior quadrant showing closed angle (a) and open angle (b)
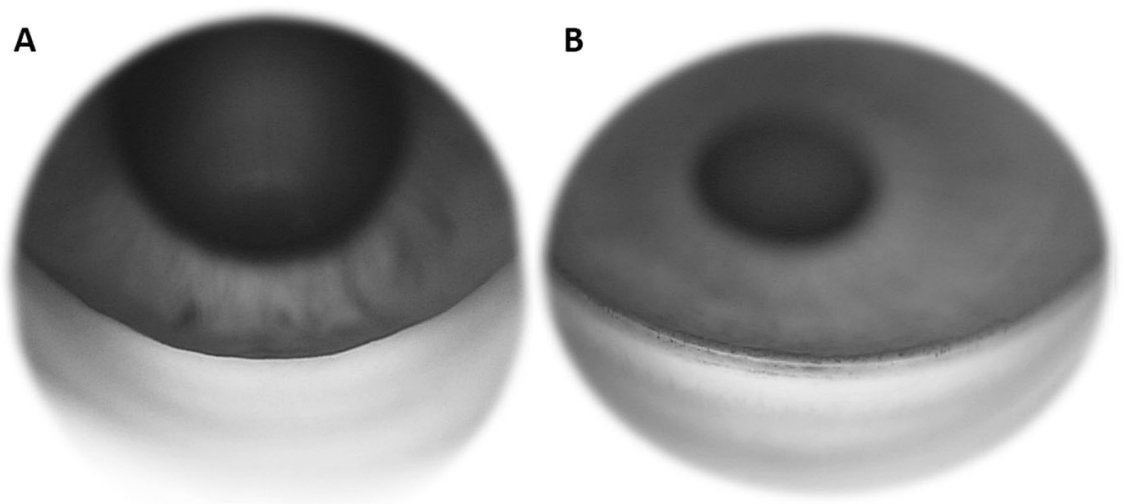

The Eyecam (Fig. 7) was originally intended to yield wide-field photographs of the fundus and was later modified to document the ACA. It is a portable handheld device that, as with gonioscopy, requires contact. It has a reported overall sensitivity of $76.2 \%$, specificity of $80.9 \%$, AUC of 0.79 to detect gonioscopic angle closure and good agreement with gonioscopy [29-31]. Baskaran et al. [32] compared gonioscopy and both manual and automated grading of EyeCam images and the agreement for angle closure diagnosis was found to be good $(\kappa=0.88$ and $\kappa=0.74$, respectively). The AUC for detecting eyes with gonioscopic angle closure was comparable for manual and automated grading (AUC 0.97 vs. $0.95, P=0.31$ ) of EyeCam images. Interestingly, $\mathrm{Xu}$ et al. [33] reported that gonioscopy and EyeCam underrepresent the amount of anatomic variation compared with AS-OCT in a Chinese-American population base study. The mean gonioscopic grade, EyeCam grade, and AS-OCT measurement for each quadrant varied by up to $10.3 \%, 6.4 \%$, and $46.2 \%$ of the superior quadrant value, respectively.

The recently developed NGS-1 automated gonioscope (NIDEK Co, Gamagori, Japan) [34] is able to capture circumferential $360^{\circ}$ gonioscopic images of the ACA in $<60 \mathrm{~s}$ per eye. Shi et at [34]. reported that not all eyes were able to be imaged with this device, as it requires good fixation and reasonable patient cooperation. There were 336 sections in total evaluated although 28 sections (8.33\%) were not gradable owing to poor image quality after manual selection. Successful imaging was also achieved of surgical devices and postsurgical conditions. The learning curve was about 1 week (mostly involving learning to align the patient's eye with the camera). One limitation is that the ability to perform dynamic (indentation) gonioscopy as during manual gonioscopy cannot be achieved with this imaging system. Another limitation is that the twodimensional images taken by this system may not provide enough depth of view for grading. As a consequence, the appearance of the iris root can be confused with the ciliary body in some cases. An earlier prototype had a low agreement with gonioscopy $(k=0.09)$ and the AUC for detecting eyes with angle closure showed poor accuracy between automated and manual methods (AUC 0.53). There was modest inter-rater agreement $(k=0.17)$ [35].

The GonioPEN combines a high-resolution miniaturized integrated charge-coupled diode (CCD) camera and lightemitting diode light source-based probe system, which enables evaluation of the iridocorneal region inside the eye. The probe can be attached to a slit lamp, providing the flexibility to be used by a nontechnical person. The imaging probe is placed near the limbal region of the cornea to image the opposite iridocorneal angle. With the use of a coupling gel, the micro-CCD camera can visualize structures in the anterior segment in a manner similar to direct gonioscopy [36].

Axicon lens assisted gonioscopy attempted to improve the gonioscope image resolution. Even though some improvements were noted, other difficulties, including lighting control, magnification adjustments, and expertize requirement associated with the slit-lamp gonioscope, still remained [37].

\section{Conclusions and future directions}

AS-OCT technology provides a noncontact method of assessing the ACA and it is more reproducible and less prone to error than slit-lamp manual gonioscopy. As it is well tolerated by the patient, it can intuitively be expected to have better acceptance among physicians. With improved resolution and lower rate of ungradable images, SS-OCT allows for first time the $360^{\circ}$ evaluation of the ACA, offering the opportunity of measuring the circumferential extension of (ITC) and PAS. These features are not possible with previous AS-OCT versions as Visante. Some disadvantages of AS-OCT technology include that it tends to diagnose more angle closure than gonioscopy. Further 
research is needed to provide the best evidence in regards of which technology is superior in identifying angle closure eyes that will progress. Another disadvantage with AS-OCT devices is that it is not possible to evaluate neovascularization or pigmentation of the angle. For that reason, gonioscopy and goniophotograph systems will still play a role in the qualitative assessment of the ACA. An exciting development in the field is the automation of the diagnosis based on deep learning algorithms that will not only aid the physician in a faster management decision but has the potential for screening in high risk populations.

Acknowledgements Images: Dr Tin A. Tun, Singapore Eye Research Institute.

\section{Compliance with ethical standards}

Conflict of interest The authors declare that they have no conflict of interest.

Publisher's note Springer Nature remains neutral with regard to jurisdictional claims in published maps and institutional affiliations.

\section{References}

1. Friedman DS, Foster PJ, Aung T, He M. Angle closure and angleclosure glaucoma: what we are doing now and what we will be doing in the future. Clin Exp Ophthalmol. 2012;40:381-7. https:// doi.org/10.1111/j.1442-9071.2012.02774.x.

2. Quigley HA, Broman AT. The number of people with glaucoma worldwide in 2010 and 2020. Br J Ophthalmol. 2006;90:262-7. https://doi.org/10.1136/bjo.2005.081224.

3. Tham Y-C, Li X, Wong TY, Quigley HA, Aung T, Cheng C-Y. Global prevalence of glaucoma and projections of glaucoma burden through 2040. Ophthalmology 2014;121:2081-90. https:// doi.org/10.1016/j.ophtha.2014.05.013.

4. Sun X, Dai Y, Chen Y, Yu D-Y, Cringle SJ, Chen J, et al. Primary angle closure glaucoma: What we know and what we don't know. Prog Retin Eye Res. 2017;57:26-45.

5. He M, Jiang Y, Huang S, Chang DS, Munoz B, Aung T, et al. Laser peripheral iridotomy for the prevention of angle closure: a single-centre, randomised controlled trial. The Lancet. 2019. https://doi.org/10.1016/S0140-6736(18)32607-2.

6. Azuara-Blanco A, Burr J, Ramsay C, Cooper D, Foster PJ, Friedman DS, et al. Effectiveness of early lens extraction for the treatment of primary angle-closure glaucoma (EAGLE): a randomised controlled trial. Lancet. 2016;388:1389-97. https://doi. org/10.1016/S0140-6736(16)30956-4.

7. Husain R, Do T, Lai J, Kitnarong N, Nongpiur ME, Perera SA, et al. Efficacy of phacoemulsification alone vs phacoemulsification with goniosynechialysis in patients with primary angleclosure disease: a randomized clinical trial. JAMA Ophthalmol. 2019. https://doi.org/10.1001/jamaophthalmol.2019.2493.

8. Husain R, Gazzard G, Aung T, Chen Y, Padmanabhan V, Oen FT, et al. Initial management of acute primary angle closure: a randomized trial comparing phacoemulsification with laser peripheral iridotomy. Ophthalmology. 2012;119:2274-81. https://doi.org/10. 1016/j.ophtha.2012.06.015.

9. Rigi M, Bell NP, Lee DA, Baker LA, Chuang AZ, Nguyen D, et al. Agreement between gonioscopic examination and swept source fourier domain anterior segment optical coherence tomography imaging. J Ophthalmol. 2016. https://doi.org/10.1155/ 2016/1727039.

10. Lavanya R, Foster PJ, Sakata LM, Friedman DS, Kashiwagi K, Wong T-Y, et al. Screening for narrow angles in the singapore population: evaluation of new noncontact screening methods. Ophthalmology. 2008;115:1720-27.e2. https://doi.org/10.1016/j. ophtha.2008.03.015.

11. Sakata LM, Lavanya R, Friedman DS, Aung HT, Gao H, Kumar $\mathrm{RS}$, et al. Comparison of gonioscopy and anterior segment ocular coherence tomography in detecting angle closure in different quadrants of the anterior chamber angle. Ophthalmology. 2008;115:769-74. https://doi.org/10.1016/j.ophtha.2007.06.030.

12. Porporato N, Baskaran M, Tun TA, Sultana R, Tan MCL, Quah JHM, et al. Assessment of circumferential angle closure with swept-source optical coherence tomography: a community based study. Am J Ophthalmol. 2019;199:133-9. https://doi.org/10. 1016/j.ajo.2018.11.015

13. Nolan WP, See JL, Chew PTK, Friedman DS, Smith SD, Radhakrishnan $\mathrm{S}$, et al. Detection of primary angle closure using anterior segment optical coherence tomography in asian eyes. Ophthalmology. 2007;114:33-9. https://doi.org/10.1016/j.ophtha. 2006.05.073.

14. Ho S-W, Baskaran M, Zheng C, Tun TA, Perera SA, Narayanaswamy AK, et al. Swept source optical coherence tomography measurement of the iris-trabecular contact (ITC) index: a new parameter for angle closure. Graefes Arch Clin Exp Ophthalmol. 2013;251:1205-11. https://doi.org/10.1007/s00417012-2158-6.

15. Baskaran M, Ho S-W, Tun TA, How AC, Perera SA, Friedman DS, et al. Assessment of circumferential angle-closure by the iris-trabecular contact index with swept-source optical coherence tomography. Ophthalmology. 2013;120:2226-31. https://doi.org/ 10.1016/j.ophtha.2013.04.020.

16. Lai I, Mak H, Lai G, Yu M, Lam DSC, Leung CKS. Anterior chamber angle imaging with swept-source optical coherence tomography: measuring peripheral anterior synechia in glaucoma. Ophthalmology. 2013;120:1144-9. https://doi.org/10.1016/j. ophtha.2012.12.006.

17. Pekmezci M, Porco TC, Lin SC. Anterior segment optical coherence tomography as a screening tool for the assessment of the anterior segment angle. Ophthalmic Surg Lasers Imaging. 2009;40:389-98.

18. Baskaran M, Ho S-W, Tun TA, How AC, Perera SA, Friedman DS, et al. Anterior segment imaging predicts incident gonioscopic angle closure. Ophthalmology 2015;122:2380-4. https://doi.org/ 10.1016/j.ophtha.2015.07.030.

19. Porporato N, Baskaran M, Tun TA, Sultana R, Tan M, Quah JH, et al. Understanding diagnostic disagreement in angle closure assessment between anterior segment optical coherence tomography and gonioscopy. Br J Ophthalmol. 2019. https://doi.org/ 10.1136/bjophthalmol-2019-314672.

20. Wang B, Sakata LM, Friedman DS, Chan Y-H, He M, Lavanya R, et al. Quantitative iris parameters and association with narrow angles. Ophthalmology. 2010;117:11-17. https://doi.org/10.1016/ j.ophtha.2009.06.017.

21. Nongpiur ME, He M, Amerasinghe N, Friedman DS, Tay W-T, Baskaran M, et al. Lens vault, thickness, and position in chinese subjects with angle closure. Ophthalmology. 2011;118:474-9. https://doi.org/10.1016/j.ophtha.2010.07.025.

22. Lavanya R, Wong T-Y, Friedman DS, Aung HT, Alfred T, Gao $\mathrm{H}$, et al. Determinants of angle closure in older singaporeans. Arch Ophthalmol. 2008;126:686-91. https://doi.org/10.1001/archopht. 126.5.686

23. Nongpiur ME, Sakata LM, Friedman DS, He M, Chan Y-H, Lavanya $\mathrm{R}$, et al. Novel association of smaller anterior chamber 
width with angle closure in Singaporeans. Ophthalmology. 2010;117:1967-73. https://doi.org/10.1016/j.ophtha.2010.02.007.

24. Tan GS, He M, Zhao W, Sakata LM, Li J, Nongpiur ME, et al. Determinants of lens vault and association with narrow angles in patients from Singapore. Am J Ophthalmol. 2012;154:39-46. https://doi.org/10.1016/j.ajo.2012.01.015.

25. Nongpiur ME, Gong T, Lee HK, Perera SA, Cheng L, Foo L-L, et al. Subgrouping of primary angle-closure suspects based on anterior segment optical coherence tomography parameters. Ophthalmology. 2013;120:2525-31. https://doi.org/10.1016/j. ophtha.2013.05.028.

26. Niwas SI, Lin W, Bai X, Kwoh CK, Jay Kuo C-C, Sng CC, et al. Automated anterior segment OCT image analysis for angle closure glaucoma mechanisms classification. Comput Methods Prog Biomed. 2016;130:65-75. https://doi.org/10.1016/j.cmpb.2016. 03.018.

27. Fu H, Baskaran M, Xu Y, Lin S, Wong DWK, Liu J, et al. A deep learning system for automated angle-closure detection in anterior segment optical coherence tomography images. Am J Ophthalmol. 2019;203:37-45. https://doi.org/10.1016/j.ajo.2019.02.028.

28. Xu BY, Chiang M, Chaudhary S, Kulkarni S, Pardeshi AA, Varma R. Deep learning classifiers for automated detection of gonioscopic angle closure based on anterior segment OCT images. Am J Ophthalmol. 2019. https://doi.org/10.1016/j.ajo. 2019.08.004.

29. Perera SA, Baskaran M, Friedman DS, Tun TA, Htoon HM, Kumar RS, et al. Use of eyecam for imaging the anterior chamber angle. Invest Ophthalmol Vis Sci. 2010;51:2993-7. https://doi. org/10.1167/iovs.09-4418.

30. Baskaran M, Perera SA, Nongpiur ME, Tun TA, Park J, Kumar RS, et al. Angle assessment by eyecam, goniophotography, and gonioscopy. J Glaucoma. 2012;21:493 https://doi.org/10.1097/ IJG.0b013e3182183362.

31. Murakami Y, Wang D, Burkemper B, Lin SC, Varma R. Group for the C-AES. A population-based assessment of the agreement between grading of goniophotographic images and gonioscopy in the Chinese-American eye study (CHES). Invest Ophthalmol Vis Sci. 2016;57:4512-6. https://doi.org/10.1167/iovs.15-18434.

32. Baskaran M, Cheng J, Perera SA, Tun TA, Liu J, Aung T. Automated analysis of angle closure from anterior chamber angle images. Invest Ophthalmol Vis Sci. 2014;55:7669-73. https://doi. org/10.1167/iovs.14-14852.

33. Xu BY, Pardeshi AA, Burkemper B, Richter GM, Lin SC, McKean-Cowdin R, et al. Differences in anterior chamber angle assessments between gonioscopy, eyecam, and anterior segment oct: the Chinese American eye study. Transl Vis Sci Technol. 2019;8:5-5. https://doi.org/10.1167/tvst.8.2.5.
34. Shi Y, Yang X, Marion KM, Francis BA, Sadda SR, Chopra V. Novel and semiautomated 360-degree gonioscopic anterior chamber angle imaging in under 60 seconds. Ophthalmol Glaucoma. 2019;2:215-23. https://doi.org/10.1016/j.ogla.2019.04.002.

35. Teixeira F, Sousa DC, Leal I, Barata A, Neves CM, Pinto LA. Automated gonioscopy photography for iridocorneal angle grading. Eur J Ophthalmol. 2018:1120672118806436. https://doi.org/ $10.1177 / 1120672118806436$.

36. Shinoj VK, Murukeshan VM, Baskaran M, Aung T. Integrated flexible handheld probe for imaging and evaluation of iridocorneal angle. J Biomed Opt. 2015;20:016014 https://doi.org/10.1117/1. JBO.20.1.016014.

37. Perinchery SM, Shinde A, Fu CY, Jeesmond Hong XJ, Baskaran M, Aung $\mathrm{T}$, et al. High resolution iridocorneal angle imaging system by axicon lens assisted gonioscopy. Sci Rep. 2016;6:30844 https://doi. org/10.1038/srep30844.

38. Campbell P, Redmond T, Agarwal R, Marshall LR. Repeatability and comparison of clinical techniques for anterior chamber angle assessment. Ophthalmic Physiol Opt. 2015;35:170-8. https://doi. org/10.1111/opo.12200.

39. Chansangpetch S, Rojanapongpun P, Lin SC. Anterior segment imaging for angle closure. Am J Ophthalmol. 2018;188:xvi-xxix. https://doi.org/10.1016/j.ajo.2018.01.006.

40. Becker SC. Unrecognized errors induced by present-day gonioprisms and a proposal for their elimination. Arch Ophthalmol. 1969;82:160-8. https://doi.org/10.1001/archopht.1969. 00990020162003 .

41. Varma DK, Simpson SM, Rai AS, Ahmed IIK. Undetected angle closure in patients with a diagnosis of open-angle glaucoma. Can J Ophthalmol J Can Ophtalmol. 2017;52:373-8. https://doi.org/10. 1016/j.jcjo.2016.12.010.

42. Varma DK, Kletke SN, Rai AS, Ahmed IIK. Proportion of undetected narrow angles or angle closure in cataract surgery referrals. Can J Ophthalmol. 2017;52:366-72. https://doi.org/10. 1016/j.jcjo.2017.01.008.

43. Quigley HA, Friedman DS, Hahn SR. Evaluation of practice patterns for the care of open-angle glaucoma compared with claims data: the glaucoma adherence and persistency study. Ophthalmology. 2007;114:1599-606. https://doi.org/10.1016/j. ophtha.2007.03.042.

44. Hertzog LH, Albrecht KG, LaBree L, Lee PP. Glaucoma care and conformance with preferred practice patterns. Examination of the private, community-based ophthalmologist. Ophthalmol. 1996;103: 1009-13. https://doi.org/10.1016/s0161-6420(96)30573-3.

45. Zebardast N, Solus JF, Quigley HA, Srikumaran D, Ramulu PY. Comparison of resident and glaucoma faculty practice patterns in the care of open-angle glaucoma. BMC Ophthalmol. 2015;15:41. 